\title{
When does an advantage become unfair? Empirical and normative concerns in Semenya's case
}

\author{
Silvia Camporesi
}

\section{Correspondence to} Dr Silvia Camporesi, Global Health \& Social Medicine, King's College London, London WC2B 4BG, UK;

silvia.camporesi@kcl.ac.uk

Received 20 April 2019

Revised 26 July 2019

Accepted 7 August 2019

Published Online First

16 September 2019
Check for updates

(c) Author(s) (or their employer(s)) 2019. No commercial re-use. See rights and permissions. Published by BMJ.

\footnotetext{
To cite: Camporesi $\mathrm{S}$.

$J$ Med Ethics
}

2019;45:700-704

\section{ABSTRACT}

There is a fundamental tension in many sports: human sex is not binary, but there are only two categories in which people can compete: male and female. Over the past 10 years, the International Association of Athletics Federations (IAAF) regulations have been at the centre of two notable legal disputes. The Court of Arbitration for Sport (CAS) reached two contradictory rulings: in the first case (Dutee Chand vs Athletics Federation India and IAAF), the IAAF regulations for the eligibility of athletes to compete in the female category were suspended (24 July 2015) on grounds of "discrimination against the female category"; in the latter (Caster Semenya and Athletics South Africa vs IAAF), the regulations were reaffirmed (1 May 2019) on grounds that although discriminatory, they are necessary to maintain a "level playing field" and to "protect" the female category. Although Semenya's case has paved the way for questioning existing gender norms in sport, a new stable norm has yet to emerge from her case. The pharmacological solution put forward by IAAF to the tension between fairness and inclusivity of bodies non-conforming to two sexes is not, however, the only possible solution/resolution to the case, as I aim to show in this paper. Here I present some reflections on this topic and suggest how CAS should approach the case if it hopes to resolve it.

\section{INTRODUCTION}

There is a fundamental tension in track and field and many other sports: human sex is not binary, but there are only two categories in which people can compete: male and female. In the late 1990s, sex testing was abandoned by the International Association of Athletics Federations (IAAF) and the International Olympic Committee (IOC) as it was agreed that it was creating more problems than the ones they were trying to solve (supposedly to identify men masquerading as women to compete in the female category). ${ }^{1}$ After a brief interval, sex testing re-emerged in 2009 with the case of the South African runner Caster Semenya, whose gold medal at the World Track and Field Championship in Berlin was revoked on suspicion of her "being a man". ${ }^{2}$ IAAF's investigation concluded that Semenya was affected by an (undisclosed) "differences of sex differentiation" condition, which provided her with high testosterone levels and gave her an unfair advantage in competition over other female athletes. In May 2011, IAAF enacted new regulations restricting the eligibility of female athletes with hyperandrogenism to compete in the female category unless under an androgen suppressive regimen to bring down the levels of testosterone to $<10 \mathrm{nmol} / \mathrm{L}$.
Over the past 10 years, the IAAF regulations have been at the centre of two notable legal disputes. The supreme arbiter of legal disputes in sport, the Court of Arbitration for Sport (CAS) based in Lausanne, Switzerland, reached two somewhat contradictory rulings: in the first case-Chand vs Athletics Federation India (AFI) and IAAF-the regulations were suspended (24 July 2015) on grounds of "discrimination against the female category"; in the latter-Semenya and Athletics South Africa (ASA) vs IAAF - the regulations were reaffirmed (1 May 2019) on grounds that, although discriminatory, they are necessary to maintain a "level playing field" and to "protect" the female category. In this latest arbitration, CAS accepted "the logic of IAAF's submission" and concluded that "restrictions on the eligibility to compete $[\ldots]$ are necessary to maintain fair competition in female athletics". ${ }^{4}$ Semenya's subsequent appeal to the Swiss Federal Tribunal in June briefly reversed the 2019 CAS Award, ${ }^{5}$ and suspended the regulations, ${ }^{6}$ but a subsequent ruling in July by the same court reversed the previous ruling, ${ }^{7}$ with the result that Semenya is unable to compete at the World Championship in Doha in September 2019.

Although Semenya's case has paved the way for questioning existing gender norms in sport, a new stable norm has yet to emerge from her case. Olivesi (2016) has defined Caster Semenya's case as an "aporia" due to the inherent tensions and apparent un-resolvability of a 10-year-old case already with no clear end in sight. ${ }^{8}$ Its apparent un-resolvability has led to the unsatisfactory-for many, including me-solution of requiring the medicalisation of otherwise physiologically healthy, although deviant from sexual binary norms, bodies. This in turn has led to the World Medical Association (WMA) to come forward with a strong statement calling on physicians not to comply with the regulations on grounds that "they are not based on medical need" and hence fall outside the recognised and widely accepted scope of medicine, which is to benefit the patients. ${ }^{9}$ As I aim to show in this paper, the IAAF's pharmacological solution to the tension between fairness and inclusivity is not the only possible solution to the problem, nor need be proposed as such.

\section{BACKGROUND TO THE CASE: THE DUTEE CHAND INTERIM ARBITRAL AWARD}

To understand the current challenge, one has to take a step back and review the critical moment in July 2015 when CAS released an interim award in the Chand vs AFI and IAAF case. ${ }^{10}$ Dutee Chand, an Indian sprinter, was affected by the IAAF hyperandrogenism regulations in 2014, and was required to take androgen suppressive treatment to be eligible 
to compete in the female category. Chand refused to comply and appealed to CAS. ${ }^{11}$ Hearings were held at the CAS headquarters in Lausanne in March 2015. On 24 July, CAS ruled that the regulations were being suspended for "absence of sufficient evidence about the degree of advantage that androgen-sensitive hyperandrogenic females enjoy over non-hyperandrogenic females (paragraph 522, interim award CAS). ${ }^{10}$ IAAF was given 2 years (later, extended by 3 months) to produce additional evidence for the correlation between endogenous testosterone and performance advantage. While the suspension of the regulations was cause for immediate relief for Chand and other hyperandrogenic athletesincluding Semenya-who were able to resume competition, a careful reading of the interim award would have shown how it was leaving space open for additional controversy. The question of what evidence would be adequate to resolve the case was already in the Chand interim award. Indeed, IAAF was quick to acknowledge that CAS had accepted the logic of their submission that a correlation between testosterone and performance advantage would settle the dispute: "The IAAF is also happy to note the CAS panel's ruling that there is a sound scientific basis to the regulations, in that endogenous testosterone is the best indicator of performance differences between male and female athletes, and its acceptance that hyperandrogenic female athletes may have a competitive advantage over athletes with testosterone levels in the normal female range". ${ }^{12}$ However, as I have argued before, ${ }^{13}{ }^{14}$ a judicial framing of the Chand case as a matter of demonstrating only a correlation between testosterone and athletic performance in female athletes falls short of establishing the unfairness of such advantage, and hence the necessity of regulations requiring athletes to lower their endogenous levels of testosterone.

\section{THE SEMENYA AND ATHLETICS SOUTH AFRICA APPEAL AGAINST IAAF 2018 REGULATIONS ON ELIGIBILITY FOR FEMALE CLASSIFICATION}

In July 2017, a study published in the British Journal of Sports Medicine written by Stephane Bermon and Pierre-Ives Garnier concluded that hyperandrogenic female athletes enjoy a degree of advantage of $1.8-2.8 \%$ over their fellow athletes in a specific set of track and field events. ${ }^{15}$ This study, commissioned and funded by IAAF and the World Anti-Doping Agency (WADA), was submitted to CAS in response to the Chand 2015 interim arbitral award. On 26 April 2018, new IAAF regulations governing the eligibility of female classification, ${ }^{16}$ which built directly on the Bermon and Garnier study, were released to come into force on 1 November 2018. The regulations required female athletes with differences of sex differentiation (DSDs) to take androgen suppressive therapy to lower their testosterone levels to $<5 \mathrm{nmol} / \mathrm{L}$ to be eligible to compete in the female category for running events between the $400 \mathrm{~m}$ and the mile $(400 \mathrm{~m}$; $400 \mathrm{~m}$ hurdles; $800 \mathrm{~m} ; 1500 \mathrm{~m}$ and the mile).

There are several concerns about the Bermon and Garnier study providing evidence for the regulation. First, several independent studies, ${ }^{17-19}$ have questioned their statistical analysis, and indicated a high likelihood of false positives. There is also an obvious conflict of interest as the main author Stephane Bermon is director of the IAAF Science and Health Department. As pointed out by Professor Roger Pielke in his expert testimony to CAS: "No other regulatory context exists where the evidence base for regulation is provided primarily by the regulatory body itself" (CAS award, page 29). ${ }^{20}$ There are also suggestions of ethical misconduct in the way in which informed consent was obtained: Bermon and Garnier's analysis relies on blood samples provided by athletes during doping control tests at the 2011 and 2013 IAAF World Championships. The athletes who had provided their blood samples had not consented to the use of their samples for anything beyond doping testing. Notwithstanding these issues, which were at the centre of ASA's legal challenge, CAS decided to admit the evidence in court. This paper is not the place to explore these points further, but I think it is quite obvious that IAAF's use of those blood samples for research into the effects of testosterone levels on female athletic performance was unethical. Consent needs to be specific to the purpose of the research unless it is clearly stated that athletes gave blanket consent for research on their blood samples. There should be higher standards for admissibility of evidence in CAS.

Two additional points are worth noting briefly before proceeding further: the lack of consensus guidelines on how to use medications safely to lower testosterone levels when used off-label (as noted by the expert testimony of Professor Marc Blockman, pp 57-58 of CAS arbitral award), ${ }^{20}$ the side effects of the medications, the difficulties of maintaining the testosterone levels below the levels requested by IAAF owing to natural fluctuations, and strict liability of the regulations on the athlete, may very well render impossible implementation of the regulations. These points were recognised by CAS in their arbitral award, where they noted "difficulties of implementation of the DSD regulations" $" 20$ and "serious concerns about the future practical application of the DSD regulations". ${ }^{21}$

\section{EMPIRICAL AND NORMATIVE CONCERNS IN SEMENYA CASE}

The press release announcing the decision to dismiss Semenya's and ASA's appeal released on 1 May 2019 noted that the CAS panel was "restrained in its task, due to the strict framework of the arbitration, to solely determine whether the DSD regulations were invalid or not". ${ }^{21}$ The executive summary of the decision further explains that the panel's function was "a purely judicial one" and that it was "neither necessary nor appropriate for the panel to step into the shoes of the IAAF by deciding how it would have approached issues had it been charged with making policies or enacting rules itself". ${ }^{4}$ The limits of the judicial role and the "strict framework of the arbitration' were, as noted, set with reference to Chand's case. On page 76-77 of the CAS arbitral award, ${ }^{20}$ IAAF writes that sports benefit from "a significant margin of appreciation in determining what is necessary and proportionate to achieve their legitimate objectives". They continue:

Accordingly, the IAAF must decide what is necessary and proportionate to achieve its aims on the basis of an honest and good faith that has a reasonable basis. As long as that test is met, it is irrelevant that others may disagree with that view, or may cite other contrary scientific evidence. Rather, in order to succeed in their challenge, the Claimants must establish that a reasonable person acting in good faith could not hold the view that the DSD regulations are necessary and appropriate to achieve the IAAF's legitimate objectives.

I find this argument simply appalling. It should not be the case that one of the two parties determine on whom the burden of proof should fall, and what this burden of proof should amount to, or what kind of standards of scientific evidence can be admitted in court. It should be up to the arbitrator to determine that. I find the fact that CAS was bound (or, felt bound) to a "strict framework for the arbitration", which limited its role to a mere judicial one, and left IAAF a wide margin of discretion in determining that the burden of proof fell on the claimants to disprove the validity of the regulations, and also a wide margin of action to determine the admissibility of evidence in the scientific 
court below the normal scientifically accepted standards, to be a significant problem for sports and international law.

In the arbitral decision, CAS also explicitly referenced the Chand interim award as a starting point for the discussion of Semenya's case, although it also explicitly stated that Semenya's case was not an appeal to the Chand case (comma 470-1, p. 122 of the arbitral award). ${ }^{20}$ In comma 474 of the CAS award the judges sum up the "factual and scientific questions" that the panel dealt with, and refer to the 'magnitude' of the advantage of testosterone as being a key question for judgement of fairness (page 123). ${ }^{20}$ This is due, as I explained in the previous section, to the judicial resolution in the 2015 Chand interim arbitral award. Although empirical data can help us answer the question of the extent to which the advantage conferred by testosterone is quantitatively different from the advantage given by other genetic and biological variations, they fall short of establishing the fairness or unfairness of the advantage. An empirical analysis of the magnitude of the advantage need only be the first, necessary although not sufficient, step in the adjudication of the case.

What type of evidence should CAS instead have been requesting, since the Dutee Chand case, and in the Semenya and ASA vs IAAF case? I think the following empirical and normative questions need to be answered:

1. In what ways is testosterone dissimilar from other genetic variations that confer a property advantage?

2. How do we treat alike cases?

Let me tackle both questions in turn.

\section{In what ways is testosterone dissimilar from other genetic variations that confer a property advantage?}

In the philosophy of sport literature, a 'property advantage' is defined as " $\mathrm{A}$ has an advantage over $\mathrm{B}$ in property $\mathrm{X}$ if $\mathrm{A}$ has a more favourable amount of this property X than B does", where properties are "constituent parts of competitors and competition environment". ${ }^{22}$ Performance advantage in a given competition is a function of many different property advantages. In what follows I refer to genetic variations that confer a property advantage as 'property advantages' for short, although there are many non-genetic factors that contribute overall to performance advantage, but they are not relevant to this discussion.

There are three key ways in which testosterone can be considered different from other property advantages, as discussed in the literature:

a. By degree of magnitude- that is, the advantage conferred by testosterone on performance advantage is greater than the advantage conferred by other biological or genetic variations.

b. By being an "all-purpose benefit" vs a "sport-specific benefit"- that is, the advantage conferred by testosterone results in a performance benefit in all sports, contrary to other advantages which are sport-specific. ${ }^{23}$

c. By virtue of playing the key role in relation to the current binary categorisation in sport-that is, testosterone is different from other biological and genetic variations because the current binary categorisation in sport is predicated on the assumption that testosterone can function as the watershed between the male and female category.

I am not going to elaborate here on each point ${ }^{24}$ However I would like to note that both (a) and (b) are open to empirical scrutiny, whereas (c) is a result of a historical convention categorising sport into binary male and female groups. At the moment, we have only limited empirical data from which we can draw comparisons between the different genetic variations and relative performance advantages. We do know that there are many genetic variations that confer a 'property advantage' and are found more frequently in elite athletes than in the general population. These allelic variations range from variations in the oxygen-carrying capacity of red blood cells, owing to mutations in the erythropoietin receptor gene (EPOR); to enzymes involved in the conversion of angiotensin (ACE) associated with increased endurance performance in athletic cohorts; to allelic variations in the $\alpha$-actinin gene (ACTN3) determining the distribution of muscular fibre types (slow or fast). ${ }^{25}$ Some of these variations lie at the border between the physiological and the pathological, depending on the context: while they can be advantageous on the field of play, they can be disadvantageous in other aspects of life. A living example was Finnish skier Eero Mäntyranta, who rose to athletic fame in cross-country skiing during the 1960s. Mäntyranta was affected by a genetic condition known as familial primary polycythaemia caused by mutations in the EPOR gene, which leads to a 30-50\% increased production of red blood cells. ${ }^{26}$ This in turn led to an increase of his oxygen-carrying capacity and gave him a formidable advantage in long-distance competitions (he had a haematocrit level of 60-65). Dr Alun Williams, sport geneticist at the University of Manchester and expert witness at CAS on behalf of Semenya, testified that "there is no clear qualitative distinction between the types of genetic variations that cause DSDs and (others)" and added that "there is no scientific basis for treating a DSD mutation as an unfair performance advantage while treating the EPOR mutation as an acceptable performance advantage" (page 34 CAS award). ${ }^{20}$ In his testimony, Williams compared the performance advantage derived by DSD mutations and the phenotypic effects of the ACTN3 allele, which is also considered an acceptable performance advantage in sprinting and power events (Williams testified that athletes who possess the ACTN3 allele are likely to "sweep the podium" in power/sprinting events (page 34 CAS award ${ }^{20}$ ). More research into the relative performance advantage conferred by testosterone compared with other property advantages in specific events in track and field (the context of the current case) or in other sports is required to answer this first question.

Point (b) is related to (a): Is there a sound basis for singling out specific sports, or sport-specific events, from others, because of the role that testosterone plays in providing athletes with a performance advantage? Scientists disagree on whether testosterone is an all-purpose benefit or a sports-specific benefit. According to some, testosterone confers a benefit on performance in all sports, contrary to other advantages which are sport-specific and allow athletes to self-select into a sport. If this were the case, it would constitute a reason to treat testosterone differently from other property advantages. However, others disagree. When reading the full arbitral award, one has the clear impression (confirmed by the statement of the executive summary in the panel that the issues were not "easy to decide", and that the "decision was reached by a majority") that while certain expert testimonies believe that testosterone is not different from other property advantages, others believe that it is. In other words, that there is a reasonable disagreement among experts which needs to be settled by further empirical evidence.

The third point (c) is not open to empirical scrutiny, but is a point that has been made by IAAF and accepted by CAS. In their testimony in front of CAS, IAAF argues that testosterone is different from other property advantages because there are no categories based on other property advantages. As noted at comma 22 of the executive award, IAAF submits that "all but

${ }^{\mathrm{i}} \mathrm{I}$ am aware that at least two teams currently working in the UK, one at the University of Loughborough and one at Sussex University, are actively working on finding the answers to the first two questions. 
one of the many different factors that contribute to sport performance are equally available to men and women", except testosterone. This point, I note, was accepted by the majority only of the CAS panel, as noted at the same comma of the executive award. While the discussion about the creation of different categories in track and field has been foreclosed by IAAF and the CAS award at the very beginning of their arbitration, where they state that the decision is "constrained by the accepted, necessary, binary division of athletics into male and female events", ${ }^{4}$ that should not, I argue, be taken as a given, or immutable element of sport. I elaborate on this point below.

To sum up, what I aimed to do in this section was to outline two keys ways in which testosterone could be considered similar to, or dissimilar from, other property advantages and which are open to empirical scrutiny, and point to a third way in which testosterone has been said to differ from other property advantages, which is based on a historical convention-that is, the binary division into male and female categories in track and field, which need not be taken for granted. Now on to the second type of normative concerns.

\section{How to treat alike cases?}

Fairness demands that alike cases are treated alike. ${ }^{27}$ Once empirical data have established whether testosterone and other property advantages can be considered alike cases, or not, we can proceed to establish how to treat them according to normative judgements of fairness. It does not follow from the fact that empirical data might have established whether testosterone and other property advantages are alike—or not-that we should prescribe pharmacological treatment to lower testosterone levels, as IAAF contends.

Let us imagine that in our parallel CAS hearing, both parties were to submit evidence in response to the first and second empirical questions. Let us also suppose that the third point of discussion (the binary categorisation) were not closed off from the start. On the basis of the submitted evidence, the CAS panel could come to two different conclusions:

1. Testosterone is different in at least one of the above respects from other property advantages.

2. Testosterone is not different in any of the above respects from other property advantages.

Let us analyse both scenarios in turn.

\section{Testosterone is different in at least one of the above respects from other property advantages}

In the first scenario, normative considerations of fairness would require testosterone to be treated differently from other property advantages. However, the pharmacological solution would be only one of the possible scenarios which would meet the demands of fairness, as I outline below. There could be at least two other options open to CAS when adjudicating the case which would do so. CAS could:

a. Maintain the binary division in male/female categories and require athletes to pharmacologically lower their levels of testosterone;

b. Abandon the binary division in male/female categories and create separate categories based on the level of testosterone or more complex algorithms;

c. Abandon the binary division in male/female categories and create categories based on external modifications to redress biological advantages.

Having agreed on the necessity and unchallengeability of the division into male and female category, the first solution is that preferred by IAAF and CAS. However, this necessity is neither apparent nor indisputable as I among others have argued-it is a consequence of historical tradition and conventions in sport. The second solution (b), while presenting challenges of feasibility and applicability, is theoretically possible and has already been explored by many including Foddy and Savulescu, ${ }^{28}$ Cooky and Dworkin, ${ }^{29}$ Sudai, ${ }^{30}$ Knox et al $l^{31}$ and Bianchi. ${ }^{32}$ Some of these scholars have gone to great lengths to suggest a feasible and practical application. Recently, Stephane Bermon, when speaking in a personal capacity to the Guardian, was reported as saying that he has the "feeling some day it will happen, and probably in 5 or 10 years". ${ }^{33}$ Hence it does not seem to be an outlandish possibility considered only by philosophers of sport, but worth exploring also by policy makers, sports lawyers and legislators to work out the details for how it might work in practice.

The third solution (c) would amount to redressing biological advantages with external, non-pharmacological interventions aimed at modifying the environment and not the athletes' bodies. It takes its cues from sports where external modifications are made to redress advantages. As noted in Camporesi ${ }^{34}$ and McNamee (2018) (p 143), in horse racing, weights are added. One could consider weighted clothing or modification of the track. Many such external modifications could be considered, which might be more respectful of the athletes' biology than pharmacological interventions. However, this solution seems less feasible in practice than solution (b) and it has been less explored in the literature.

\section{Testosterone is not different in any of the respects above from other property advantages}

What if CAS were to conclude, on the basis of the submitted evidence to the first two empirical questions, that testosterone is not different from other property advantages in any of the above respects? Would that easily settle the matter in favour of Semenya and Chand? One might think so, but on reflection it would become evident that the solution about how to treat alike cases would not follow from empirical data only. There could still be at least three other possible options for how to resolve the case, which would be in line with the requirements of fairness, but which would differ in other considerations. CAS, as the arbitrator, could decide to:

a. Maintain the binary division and let athletes compete with the bodies they are born with (a version of the natural/genetic lottery argument);

b. Abandon the binary division and consistently redress all genetic inequalities in favour of a "level playing field" understanding of fairness applied to each type of inequality for which we would have scientific evidence. This could be achieved in three ways:

- by lowering levels of hormones/proteins above a certain threshold;

- by creating separate categories based on the level of biological variations;

- by creating categories based on external modifications not aimed at intervening in the athletes' bodies.

The careful reader will already have noted how these last three scenarios are iterations of the scenarios we encountered in the previous section. Expert witness Alun Williams noted in his testimony that the only difference between testosterone and other biological or genetic variations is that, presently, "It is not known which elite athletes have which advantageous genetic variations" (CAS award, 1 May, p. 34). This article is not the place to explore in detail each option and its feasibility. However, I would like to note that once we begin (as we have) to know more about the genetic basis of sports performance, we 
open up a can of worms for normative judgements of fairness of how to treat alike cases. ${ }^{\mathrm{ii}}$ This means that when conducting more research into the genetic basis of sport performance, different solutions (including some surprising ones!) about how to regulate competition on grounds of fairness might arise.

\section{CONCLUSIONS}

My goal in this paper has been to outline the shortcomings of the way in which the Semenya and ASA vs IAAF case and previously Dutee Chand vs AFI and IAAF have been judicially framed. I have argued that the grounds on which the CAS 2015 interim arbitral award was established were too narrow as they were based on empirical concerns only, and set up the current case for a further aporia (as Olivesi would say), as more evidence of the type requested by CAS cannot lead to a normative resolution of the case. The key point of this paper is that the question of what to do with that evidence is a normative question, which necessarily involves examination of empirical data to ascertain in what ways, if any, testosterone is dissimilar from other property advantages. Once empirical data have led us to establish whether we are dealing with 'alike cases', or not, the normative question of how to treat alike cases on the basis of fairness ensues. It does not follow from the establishment that testosterone confers more of an advantage than other variations, that we need to suppress it. Other scenarios are possible, which would meet the requirement of fairness to treat alike cases alike. These would require challenging the binary division into male/female categories. As noted above, these are theoretically appealing scenarios to be considered by philosophers and also by policy makers and legislators.

Importantly, CAS, as the supreme arbitrator in legal disputes in international sports law, should not be constrained in how it can adjudicate the case to a 'purely judicial role' limiting it to decide whether regulations are invalid or not, but should instead retain the discretion to decide whether such policies or rules should be enacted in the first place: Are they the best possible solution to respond to the tensions in sport and to demands of fairness and inclusivity?

Acknowledgements I am grateful to Jim Parry, Irena Martinkova and all of the terrific students in the Erasmus Mundus MA in Sports Integrity and Ethics funded by the European Union for their smart questions to my discussion of the topic. Many thanks also to the two anonymous reviewers for their helpful comments.

Contributors I am sole author of this paper.

Funding The authors have not declared a specific grant for this research from any funding agency in the public, commercial or not-for-profit sectors.

Competing interests None declared.

Patient consent for publication Not required.

Provenance and peer review Not commissioned; externally peer reviewed.

ORCID iD

Silvia Camporesi http://orcid.org/0000-0003-4135-1723

\section{REFERENCES}

1. Heggie V. Testing sex and gender in sports; reinventing, reimagining and reconstructing histories. Endeavour 2010;34(4):157-63.

2. Camporesi S, Maugeri P. Caster Semenya: sport, categories and the creative role of ethics. J Med Ethics 2010;36(6):378-9.

3. International Association of Athletics Federations. IAAF regulations governing eligibility of females with hyperandrogenism to compete in the female category in

${ }^{\text {ii } I ~ a m ~ g r a t e f u l ~ t o ~ J i m ~ P a r r y ~ a n d ~ t h e ~ s t u d e n t s ~ o f ~ t h e ~ M A i S I ~}$ Erasmus Programme for this suggestion. force may 1st, 2011-July 24th, 2015. Available: https://silviacamporesiresearchdotorg. files.wordpress.com/2016/08/iaafguidelineseligibilityhyperandrogenism1my2011.pdf

4. Court of Arbitration for Sport. CAS executive summary in the Semenya and ASA vs IAAF case released April 30th 2019, 2019. Available: https://www.tas-cas.org/ fileadmin/user_upload/CAS_Executive_Summary__5794_.pdf

5. Sports 24. Caster free to run as Swiss Supreme Court suspends IAAF ruling, 2019 Available: https://www.sport24.co.za/OtherSport/Athletics/caster-free-to-run-asswiss-supreme-court-suspends-iaaf-ruling-20190603

6. BBC Sports. Caster Semenya: Swiss Court rejects IAAF Request to re-impose testosterone rules. Available: https://www.bbc.com/sport/athletics/48630087

7. Press Association. Caster Semenya unable to defend $800 \mathrm{~m}$ title following Court ruling, July 30th, 2019. Available: https://www.theargus.co.uk/uk_national_sport/ 17804865.caster-semenya-unable-defend-800m-title-following-court-ruling/

8. Olivesi A. From the implicit to aporia: the specificities of the Caster Semenya case as a "discursive moment". In: Montañola S, ed. Gender Testing in Sport: ethics, cases and controversies. Routledge, 2016: 103-14.

9. The World Medical Association. World Medical Association urges physicians not to implement IAAF rules on classifying women athletes, 2019. Available: https:// www.wma.net/news-post/wma-urges-physicians-not-to-implement-iaaf-rules-onclassifying-women-athletes/

10. CAS Interim Arbitral Award in the Dutee Chand v. AFI \& IAAF Case, 2015. Available: https://www.tas-cas.org/fileadmin/user_upload/award_internet.pdf

11. The Times of India. Allow me to run just as I was born: Dutee to IAAF, 2017. Available: https://timesofindia.indiatimes.com/sports/more-sports/athletics/allow-me-to-run-justas-i-was-born-dutee-to-iaaf/articleshow/59467351.cms

12. IAAF. IAAF Comments on interim award issued by the CAS on the IAAF's hyperandrogenism regulations, 2019. Available: https://www.iaaf.org/news/pressrelease/hyperandrogenism-regulations-cas-dutee-chand

13. Camporesi S. Clear skies overhead for Dutee Chand, but clouds Loom on the horizon, 2016. Available: https://www.huffpost.com/entry/clear-skies-overhead-for_b_ 7896924

14. Camporesi $S$. Ethics of regulating competition for women with hyperandrogenism. Clin Sports Med 2016:35(2):293-301.

15. Bermon S, Garnier P-Y. Serum androgen levels and their relation to performance in track and field: mass spectrometry results from 2127 observations in male and female elite athletes. Br J Sports Med 2017:51(17):1309-14.

16. IAAF eligibility regulations for female classification (athletes with differences of sex developments), relased April 23rd, 2018, due to come in force November 1st, 2018 , suspended for the duration of the CAS proceedings, in force from May 1st, 2019, 2019. Available: http://www.femede.es/documentos/IAAF_Eligibility_Regulations_ DSD-2018.pdf

17. Sőnksen PH, Bavington LD, Boehning T, et al. Hyperandrogenism controversy in elite women's sport: an examination and critique of recent evidence. Br I Sports Med 2018:52(23):1481-2

18. Franklin S, Ospina Betancurt J, Camporesi S. What statistical data of observational performance can tell us and what they cannot: the case of Dutee Chand v. AFI \& IAAF. Br J Sports Med 2018:52(7):420-1.

19. Pielke R, Tucker R, Boye E. Scientific integrity and the IAAF testosterone regulations. Int Sports Law J 2019:4(23):1-9.

20. CAS Arbitral award in the arbitration between Caster Semenya, athletics South Africa and the International Association for Athletics Federation, released June 18th, 2019. Available: https://www.tas-cas.org/fileadmin/user_upload/Media_Release_Semenya_ ASA_IAAF_publish_readacted_award.pdf

21. Court of Arbitration for Sport. CAS press release with decision Semenya and ASA vs IAAF case, 2019. Available: https://www.tas-cas.org/fileadmin/user_upload/Media_ Release_Semenya_ASA_IAAF_decision.pdf

22. Hämäläinen M. The concept of advantage in sport. Sport, Ethics and Philosophy 2012;6(3):308-22.

23. Bianchi A. Transgender women in sport. J Philos Sport 2017;44(2):229-42.

24. Camporesi S. and Hämäläinen, M. fforthcoming 2019.

25. Pitsiladis $Y$, Wang G, Wolfarth $B$, et al. Genomics of elite sporting performance: what little we know and necessary advances. Br J Sports Med 2013:47(9):550-5.

26. Perrotta $\mathrm{S}$, Cucciolla V, Ferraro $\mathrm{M}$, et al. Epo receptor gain-of-function causes hereditary polycythemia, alters $\mathrm{CD} 34^{+}$cell differentiation and increases circulating endothelial precursors. PLoS One 2010:5(8):e12015.

27. Loland S. Fair play in sport: a moral norm system. Routledge, 2013.

28. Foddy B, Savulescu J. Time to re-evaluate gender segregation in athletics? Br J Sports Med 2011;45(15):1184-8

29. Cooky C, Dworkin SL. Policing the boundaries of sex: a critical examination of gender verification and the Caster Semenya controversy. J Sex Res 2013:50(2):103-11.

30. Sudai M. The testosterone rule-constructing fairness in professional sport. J Law Biosci 2017:4(1):181-93

31. Knox T, Anderson LC, Heather A. Transwomen in elite sport: scientific and ethical considerations. J Med Ethics 2019;45(6):395-403.

32. Bianchi A. Something's got to give: reconsidering the justification for a gender divide in sport. Philosophies 2019;4(2).

33. Igle S.. Court has Semenya's career in its hands - and decision could affect all of sport. The Guardian. Available: https://www.theguardian.com/sport/blog/2019/feb/ 18/caster-semenya-testosterone-levels-female-sport-court

34. Camporesi S, McNamee M. Bioethics, genetics and sport. Routledge, 2018. 